\title{
GIS Application in Mapping Institutional Participants of National Survey of Student Engagement (NSSE)
}

\author{
Xiao Yuan \\ College of Education \\ Niagara University \\ 5795 Lewiston Rd, NY 14109 \\ United States
}

\begin{abstract}
This research aims at demonstrating the distributions and changes of US participating institutions in National Survey of Student Engagement (NSSE) from year 2014 to 2016. Arc GIS (Geographic Information System) is used as the research method and maps are produced in accordance with the number of participants. Readers and NSSE current participating institutions and possible future participating institutions can attain a straightforward image of the geographical distribution of participating institutions in mainland states of the US and the distribution of different degree-level participating institutions, from which they can distinguish the changes over time.
\end{abstract}

Keywords: GIS, NSSE, institutions, mapping, changes

\section{GIS Application in Mapping Institutional Participants of National Survey of Student Engagement (NSSE)}

National Survey of Student Engagement (NSSE) is a third-party survey administration organization which annually collects information at hundreds of four-year colleges and universities about first-year and senior students' participation in programs and activities that institutions provide for their learning and personal development, to provide an estimate of how undergraduates spend their time and what they gain from attending college. Since launch in 2000, every year an increasing number of institutions have participated in NSSE to identify aspects of the undergraduate experience inside and outside the classroom that can be improved through changes in policies and practices more consistent with good practices in undergraduate education. NSSE information is also used by prospective college students, their parents, college counselors, academic advisers, institutional research officers, and researchers to learn more about how students spend their time at different colleges and universities and what they gain from their experiences. However, there are doubts about the validity and reliability of NSSE benchmarks and also there is voice for improvement of the instrument for better facilitating the participating institutions.

The research starts with the following hypotheses:

1. There is a decrease in the number of participating institutions if NSSE survey results is not beneficial to the institutions.

2. Participating institutions geographical distribute in different regions of the United States if the NSSE participants changed significantly.

3. Level of institutions should change greatly over the time if there are large differences in the number of participating institutions each year.

Equipped with these hypotheses, the research focused on the U.S. participating institutions of the NSSE from 2014 to 2016. The data were collected from the NSSE official website, from which the number of participating institution in each state was collected as well as the number of participating institutions of each degree-level. By applying the Arc GIS map 10, the data was transferred into maps showing the distributions and variations.

The research result demonstrated that the NSSE participating institutions were situated in the mainland US, especially in the Mideast and Northeast regions, with some scattering in the South region as well, but in the West Region, California was the only significant state with great number of participating institutions. In the duration of the three years, no significant differences occurred in the geographic distributions. New York State, Pennsylvania, Texas, California and Ohio were the top five states with most participating institutions, followed by Georgia, Massachusetts, Illinois, North Carolina, Indiana, only a little fluctuation was observed in the numbers and distributions.

The dominating participating institutions were Master level institutions, which were much significantly higher than the number of doctoral level and baccalaureate level.

This research result demonstrated that NSSE holds a steady number of participating institutions with a slight increase each year, and most participating institutions participated in NSSE continuously, which might show that NSSE survey result may have benefited significantly to the participating institutions in certain ways. 
The limitation of this research is that it only explored the current situation of the NSSE, but it did not predict the future trend of participating; the research compared the data of the latest three years which may not reveal much differences; this research did not discover any reasons of this distribution. Future research could use further GIS research method to predict the future trend, and could collect data in a longer duration thus reasons of the variation may be explored.

This research could be useful for both institutions who are participating in the NSSE and also the future participating institutions to have a thorough image of the participants in terms of the geographic distribution in mainland United States and the differences of all degree-levels, which offers useful information for policy makers of institutions.

\section{Literature Review}

There is only a small body of literature focusing on the participating institutions of National Survey of Student Engagement (NSSE).The existing research mainly focused on the NSSE data results of evaluation functioning for improvement of institutions per se (Vaughan \& Cloutier, 2017; Chen, Gonyea, Sarraf, BrckaLorenz, Korkmaz, Lambert \&Williams, 2009; McCormick, Gonyea, \& Kinzie, 2013; Pike, 2013). Some research emphasized on NSSE validity and reliability (Campbell \& Cabrera, 2011; Gordon, Ludlum, \& Hoey, 2008; Price \& Baker, 2012; Lerer \& Talley, 2010; Pike, 2004). One research compared data of NSSE with the peer students in New Zealand (Comer \& Brogt 2012). Another research discussed about the neglect of student comment at the end of the survey instrument (Chambers, 2010). Some researchers (Payne, Kleine, Purcell, \& Carter2005) suggested that the institutional administrators integrate its own surveys with NSSE survey data for accuracy reason before decision making and policy practice. Pike (2006) suggested NSSE to add four to five survey items on college or department level in order to help college or department to revise their policies in future practice.

From the literature and the official website of NSSE, the author found that there are five benchmarks of the NSSE instrument measured on a score of $0-100$, which includes

* Level of Academic Challenge (LAC)

* Active and Collaborative Learning (ACL)

* Enriching Educational Experiences (EEE)

* Student-Faculty Interaction (SFI)

* Supportive Campus Environment (SCE)

Campbell \& Cabrera (2011) summarized the function of the five benchmark as “...the NSSE five Benchmarks of Effective Educational Practice reflect the two sides of the engagement equation: what the student does to become involved, and what the institution does to create meaningful engagement experiences. The Level of Academic Challenge benchmark ascertains the rigor of coursework in terms of academic effort and higher order thinking, such as time spent preparing for class and coursework emphasis on analysis (Pike et al., 2011). The Active and Collaborative Learning benchmark assesses whether students are asked to reflect on and apply their learning and to work with other students-for example, working with peers on projects, asking questions in class, or making class presentations. The Student-Faculty Interaction benchmark assesses students' contact with faculty both in and out of class. The Enriching Educational Experiences benchmark covers a variety of educationally purposeful learning activities, such as study abroad experiences, conversations with diverse others, and research with faculty. Finally, the Supportive Campus Environment benchmark taps student relationships with faculty, administrators, and students and institutional support of student success."

By using this framework, NSSE is "to facilitate comparisons across time, as well as between individual institutions and types of institutions" (NSSE, 2009). Though NSSE doesn't assess student learning directly, the survey results point to areas where colleges and universities are performing well and aspects of the undergraduate experience that could be improved.

Since 2000 when NSSE was launched, a large number of institutions have used NSSE data to identify aspects of the undergraduate experience inside and outside the classroom that can be improved through changes in policies and practices more consistent with good practices in undergraduate education. NSSE information is also used by prospective college students, their parents, college counselors, academic advisers, institutional research officers, and researchers to learn more about how students spend their time at different colleges and universities and what they gain from their experiences. However, there are doubts about the validity and reliability of NSSE benchmarks and also there is voice for improvement of the instrument for better facilitating the participating institutions.

What's more, after a careful reading of the recent literature about NSSE, the author noticed that there is a gap on the research of NSSE from the perspectives of institutions. Also from the official website of NSSE, no map of geographic locations of the institutions can be found. Therefore, this research is to fill in the gap to give light on a new perspective of research on NSSE and its participants. 
This paper is aiming at mapping the variations of institution participants of the US from 2014 to 2016 using the method of Geographical Information System, to give institutions, students, parents and other stakeholders a picture of the trend for future analysis of the implicit and explicit causes for the variations.

This research focuses on the U.S. participants of the NSSE in a duration of three years in order to see the variations in the distribution of NSSE participating institutions to discover whether NSSE has a steady participants and how is the geographic distribution and if there is any changes in the distributions across the years.

\section{Research Hypotheses}

By reading the institution participants of each year from NSSE official website, the author noticed that the total number of participants does not differ much each year, but a significant number of institutions stopped participating in the middle, and re-participated later on. Also, in some states there are obviously more participants than other states, for example, the number of institutions in Texas which engaged in the NSSE is much smaller than that of California and New York, though these three states are reported the top three states holding international students(Open doors, 2016). On noticing that, the researcher wonders if there is a state difference in the participation each year. Therefore, the hypotheses of this research are that:

1. There is a decrease in the number of participating institutions if NSSE survey results is not beneficial to the institutions.

2. Participating institutions geographical distribute in different regions of the United States if the NSSE participants changed significantly.

3. Level of institutions should change greatly over the time if there are large differences in the number of participating institutions each year.

\section{Research Questions}

1. What is the geographical distribution of NSSE participating institutions in the US mainland states?

2. What is the geographical distribution of NSSE participating institutions of different degree levels?

3. What are the changes of the institution participants over the years, if there are any?

\section{Methodology}

In this research, the author will use the public data from the NSSE official website. The data consists of numbers and states of U.S. participating institution in 2014 to 2016. By using Geographical Information System, a statebased map shape file will be applied first, then the mainland US shape file will be produced, on which the four regions will be layered. The data will explore and map the distributions of the states with the largest number of participating institutions.

\section{The GIS model design is illustrated in Figure 1. GIS Model Design}

\section{Data input}

1. The number of participants in each state will be shown by Density distribution. Dots will demonstrate the differences across states, the more dots the more participants a state holds. Three maps with dots representing three academic years will be displayed.

2. The number by institution level of each state will be displayed by bar chart. For example, in academic year 2014-2016, in New York State there are nineteen institution participants, which is the highest of all. In the bar chart of New York State, the doctoral institutions, Master's institutions, Baccalaureate institutions are compared. Three maps will be produced.

3. Data collected from NESS (2014-2016) will be recoded into different fields and rows. States will go into rows and number of participating institutions will go into separated field. There are eight separated fields regarding the three levels of doctoral universities, three levels of Master's universities and two levels of Baccalaureate institutions. The total number of doctoral levels institutions, Master's level institutions, Baccalaureate institutions and the total number of institutions of all eight categories will be in a field.

4. Three academic years from 2014 to 2016 will be compared and demonstrated.

\section{Map output}

1. One US state-based map will show the distribution of the participating institutions in each US map in academic year 2014 to 2016.

2. Three US state-based maps with 4-region layers will show the level of participants in each state will be produced.

3. US state-based shape files will be needed and US nine-region shape files as well. Three maps with total participant location will be produced, showing the location of the participants 2014 to 2016 academic years. US 4-region map will demonstrate the distribution of those institutions as another layer. 
4. On the US state-based map, the top states with highest participants( $>=30)$ will be demonstrated with bar charts showing the differences of three-degree level of institutions, namely the doctorate levels, the Master's level and the Baccalaureate level.

\section{Results and Discussions}

Table 1 shows the top 10 states with 30 participating institutions of NSSE from the official website, and the raw number of all participating states is shown in Table 2. From the tables readers can see that New York State is the dominant state with most participating institutions in the three years, though in year 2015, there was a big level-off. However, the number of participants in 2015 experienced a level-off for all top states, not only in the New York State. Reasons need to be explored in terms of this interesting change.

Figure 2. Figure 3. Figure 4 are reporting the States with NSSE Institution Participants $(>=30)$, which are shown in three layers: the year data 2014 (or 2015, 2016), the four regions of mainland US, and the mainland US. From the map set, it is easy to notice that the majority of NSSE Institution Participants from 2014 to 2016 located in the lower part of Northeast, Mideast and South Regions, with California the only state from the West Region. Second, top states with the most NSSE institution participants are: New York States, Pennsylvania, Texas, California, Ohio, Illinois, North Carolina and Massachusetts, while Indiana and Georgia were both among the top states in 2014, but they shifted in 2015 and 2016. See Figure 2. Figure 3. Figure 4.

Table 2, Figure 5. Figure 6. Figure 7 compare the differences in the participating institution levels from 2014 to 2016. From the maps, readers can find that doctoral-level institution participants were the fewest in any top states, which is reasonable as there are much fewer doctoral-level institutions than the other two. New York State, California, Texas had most doctoral-level institutions participating in NSSE during the past three years. One thing interesting is that in Ohio, the number of doctoral-level institutions participating in NSSE was almost the same number of its master-level's. Masters-level institutions dominated in all states, especially in New York State, California, Texas, Indiana and Illinois, where Masters-level institutions were much more than the doctoral-level and baccalaureate-level institutions. Baccalaureate-level institutions participants mainly located in New York State, Pennsylvania, North Carolina, Ohio and Georgia, while Carolina and Georgia had the more baccalaureate-level institutions than Masters-level institutions.

Figure 8. Figure 9. Figure 10 display the changes of participating institution levels in each top state during 2014 and 2016. The doctoral-level institution participants changed significantly during this period. California, Ohio, Illinois and Pennsylvania experienced a slight decrease but Indiana doctoral-level Institution participants dropped dramatically in 2016. In Texas, Georgia and Massachusetts, more doctoral-level institution participants participated in NSSE from 2014 to 2016. North Carolina had a steady number of doctoral-level institutions participants, but doctoral-level institutions of New York State had dramatic fewer participants in 2015 than the other two years, though New York State was still the dominant state with most total number of institution participant in 2015, its number of doctoral-level institutions was much fewer that of Texas.

Interestingly, for master-level institutions in the major states, including New York State, Pennsylvania, California and Georgia, it had an obvious drop in 2015 and then it increased again in 2016.Texas is the only state whose master-level institutions steadily increased during the time. The situation in Illinois, Ohio and North Carolina and Massachusetts experienced a slight decrease. Baccalaureate-level institutions were mainly located in New York State, Pennsylvania, North Carolina and Georgia, though number of that in both New York State and Pennsylvania dropped in 2015. North Carolina and Georgia had a lot Baccalaureate-level Institutions participating in NSSE.

The result from this research explored the differences and changes in the geographical distribution of NSSE participants, which apparently displays that the main participants are stable. This could explain that the NSSE is found useful by those participating institutions, because they choose to continuously engage in this survey, though it costs high each year. Another point that could be implied is that the NSSE has conducted an effective marketing in the states with the most participating institutions. But the states with the most participating institutions are not necessarily the states with the most universities. Thus the marketing plan for NSSE could be adjusted to expand the participating rates. It seems that there are not significant changes in other states in terms of the participants, from which policies could be carefully observed to see the reasons of that.

For participating institutions, it is useful to know the phenomenon of the counterparts and make possible change in the policy from all levels within institutions.

\section{Conclusion}

This research holds the strength of its new perspective of researching on NSSE and its participants. The data of this research is the public data of NSSE. The GIS methodology is the main technique which makes it different from other research. In the application of the GIS technology, the author demonstrated the distribution of the participants on the map and by comparing the data of three academic years, the result would be useful not only for policy 
makers of NSSE, but also will be applicable to the participating institutional policy makers in deciding whether to join continuously or not. Furthermore, the map will help US college students and international students and parents to have a clear picture of the universities and their quality of education in the institutions, as those participating institutions surely cares much about their students' engagement in and out of class activities.

A limitation of this research is that there is no substantial literature in this field and the author could not attain enough resources which may result in a low reliability. Additionally, the three compared academic years are too close to identify significant differences.

\section{References}

Campbell, C. M., \& Cabrera, A. F. (2011). How sound is NSSE? Investigating the psychometric properties of NSSE at a public, research-extensive institution. The Review of Higher Education, 35(1), 77-103.

Chambers, T. (2010). What I hear you saying is: Analysis of student comments from the NSSE. College Student Journal, 44(1), 3.

Chen, P. D., Gonyea, R. M., Sarraf, S. A., BrckaLorenz, A., Korkmaz, A., Lambert, A. D., Williams, J. M. (2009). Analyzing and interpreting NSSE data. New Directions for Institutional Research, 2009(141), 35-54. doi:10.1002/ir.285

Comer, K., Brogt, E., (2012). Interpreting differences between the United States and New Zealand university students' engagement scores as measured by the NSSE and AUSSE. Assessment \& Evaluation in Higher Education, 38(6), 713.

Gordon, J., Ludlum, J., \& Hoey, J. J. (2008). Validating NSSE against student outcomes: Are they related? Research in Higher Education, 49(1), 19-39. doi: 10.1007/s11162-007-9061-8

Open doors. (2016). Institute of International Education "Top 25 Institutions Hosting International Students, 2015/16." Open Doors Report on International Educational Exchange. Retrieved from http://www.iie.org/opendoors

Lerer, N., \& Talley, K. (2010). National survey of student engagement's (NSSE) benchmarks - one size fits all? On the Horizon, 18(4), 355. doi:10.1108/10748121011082653

McCormick, A. C., Gonyea, R. M., \& Kinzie, J. (2013). Refreshing engagement: NSSE at 13.Change, 45(3), 6-15. doi:10.1080/00091383.2013.786985

NSSE. National Survey of Student Engagement. (2009). Assessment for improvement: Tracking student engagement over time-annual results 2009. Bloomington: Indiana University Center for Postsecondary Research.

Payne, S. L., Kleine, K. L. M., Purcell, J., \& Carter, G. R. (2005). Evaluating academic challenge beyond the NSSE. Innovative Higher Education, 30(2), 129-146. doi:10.1007/s10755-005-5015-2

Pike, G. R. (2004). Measuring quality: A comparison of U.S. news rankings and NSSE benchmarks. Research in Higher Education, 45(2), 193-208. doi:10.1023/B:RIHE.0000015695.84207.44

Pike, G. R. (2006). The dependability of NSSE scale lets for college- and department-level assessment. Research in Higher Education, 47(2), 177-195. doi:10.1007/s11162-005-8885-3

Pike, G. R. (2013). NSSE benchmarks and institutional outcomes: A note on the importance of considering the intended uses of a measure in validity studies. Research in Higher Education, 54(2), 149-170. doi:10.1007/s11162-012-9279-y

Price, K., \& Baker, S. N. (2012). Measuring students' engagement on college campuses: Is the NSSE an appropriate measure of adult students' engagement? The Journal of Continuing Higher Education, 60(1), 20-32. doi:10.1080/07377363.2012.649127

Vaughan, N., \& Cloutier, D. (2017). Evaluating a blended degree program through the use of the NSSE framework. British Journal of Educational Technology, 48(5), 1176-1187. doi:10.1111/bjet.12537 
Appendix

\begin{tabular}{lllll}
\hline State & STUSPS & No2016 & No2015 & No2014 \\
\hline New York & NY & 75 & 58 & 89 \\
\hline Pennsylvania & PA & 64 & 52 & 66 \\
\hline Texas & TX & 56 & 53 & 44 \\
\hline California & CA & 55 & 45 & 60 \\
\hline Ohio & OH & 42 & 40 & 38 \\
\hline Georgia & GA & 38 & 26 & 35 \\
\hline Massachusetts & MA & 36 & 33 & 37 \\
\hline Illinois & IL & 34 & 36 & 42 \\
\hline North Carolina & NC & 33 & 34 & 30 \\
\hline Indiana & IN & 23 & 30 & \\
\hline
\end{tabular}

Table 1. 2014-2016 States with NSSE Institution Participants (>=30)

\begin{tabular}{|c|c|c|c|c|c|c|c|c|c|c|}
\hline State & $\begin{array}{l}\text { STUS } \\
\text { PS }\end{array}$ & $\begin{array}{l}\text { Doc } \\
2014\end{array}$ & $\begin{array}{l}\text { Mas } \\
2014\end{array}$ & $\begin{array}{l}\mathrm{Ba} \\
2014\end{array}$ & $\begin{array}{l}\text { Doc } \\
2015\end{array}$ & $\begin{array}{l}\text { Mas } \\
2015\end{array}$ & $\begin{array}{l}\mathrm{Ba} \\
2015\end{array}$ & $\begin{array}{l}\text { Doc } \\
2016\end{array}$ & $\begin{array}{l}\text { Mas } \\
2016\end{array}$ & $\begin{array}{l}\mathrm{Ba} \\
2016\end{array}$ \\
\hline California & $\mathrm{CA}$ & 10 & 33 & 10 & 10 & 22 & 8 & 8 & 32 & 9 \\
\hline Georgia & GA & 8 & 13 & 12 & 5 & 6 & 13 & 9 & 12 & 16 \\
\hline Illinois & $\mathrm{IL}$ & 7 & 21 & 9 & 8 & 18 & 6 & 6 & 17 & 8 \\
\hline Indiana & IN & 3 & 13 & 13 & 4 & 14 & 10 & 1 & 12 & 9 \\
\hline $\begin{array}{l}\text { Massachuse } \\
\text { tts }\end{array}$ & MA & 8 & 16 & 8 & 7 & 16 & 7 & 9 & 15 & 9 \\
\hline $\begin{array}{l}\text { North } \\
\text { Carolina }\end{array}$ & $\mathrm{NC}$ & 5 & 15 & 17 & 5 & 12 & 17 & 5 & 11 & 17 \\
\hline New York & NY & 15 & 43 & 26 & 9 & 30 & 16 & 13 & 33 & 26 \\
\hline Ohio & $\mathrm{OH}$ & 11 & 13 & 10 & 11 & 12 & 13 & 9 & 11 & 17 \\
\hline $\begin{array}{l}\text { Pennsylvani } \\
\text { a }\end{array}$ & PA & 6 & 29 & 28 & 6 & 22 & 23 & 5 & 33 & 25 \\
\hline Texas & $\mathrm{TX}$ & 12 & 21 & 9 & 16 & 29 & 6 & 17 & 28 & 10 \\
\hline
\end{tabular}

Table 2. Number of Institution Participants of all degree levels (2014-2016) in Top States 
Numbers and belonging State of NSSE participating institutions in 2014-2016

Numbers of each degree-level NSSE participating institutions in 20142016

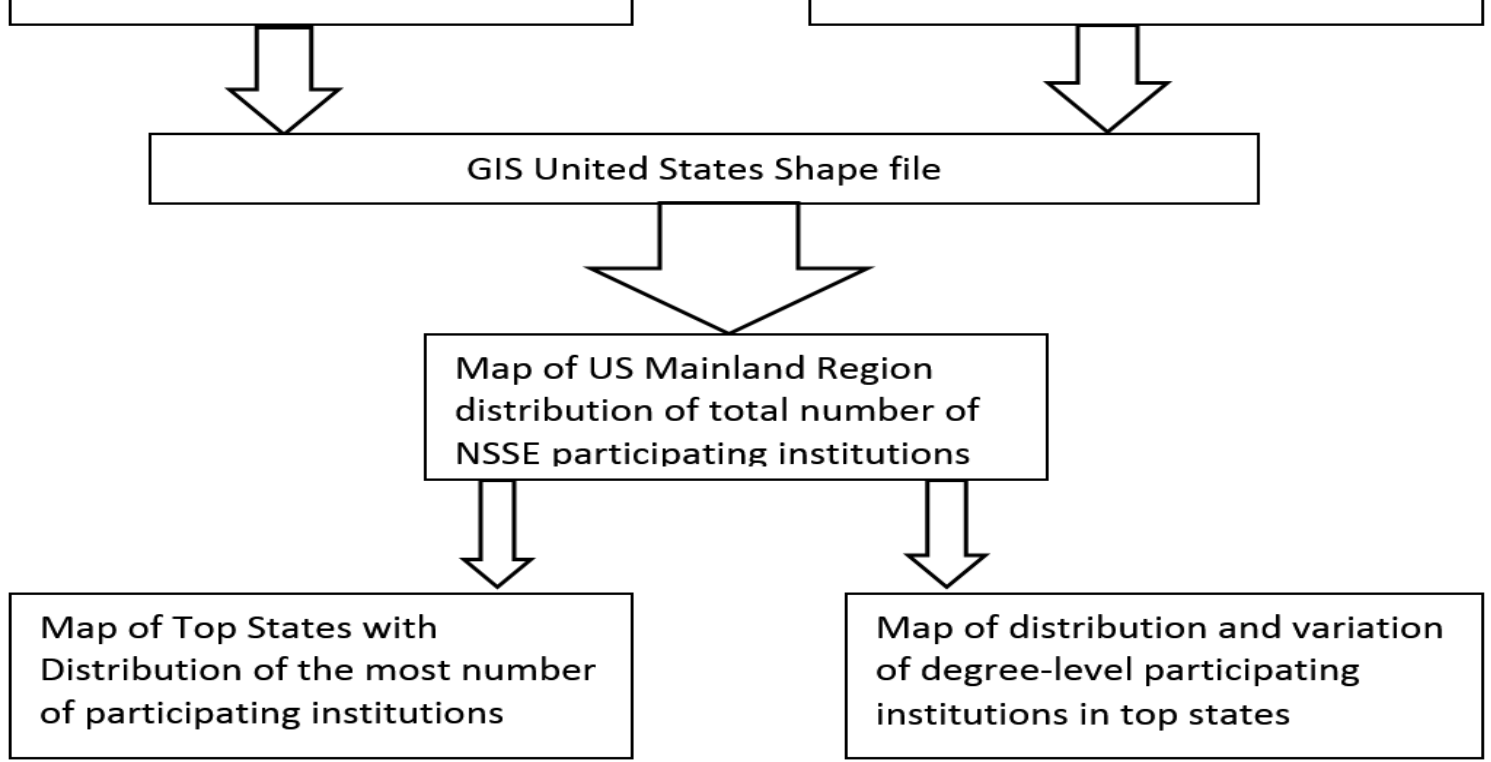

Figure 2. GIS Model Design

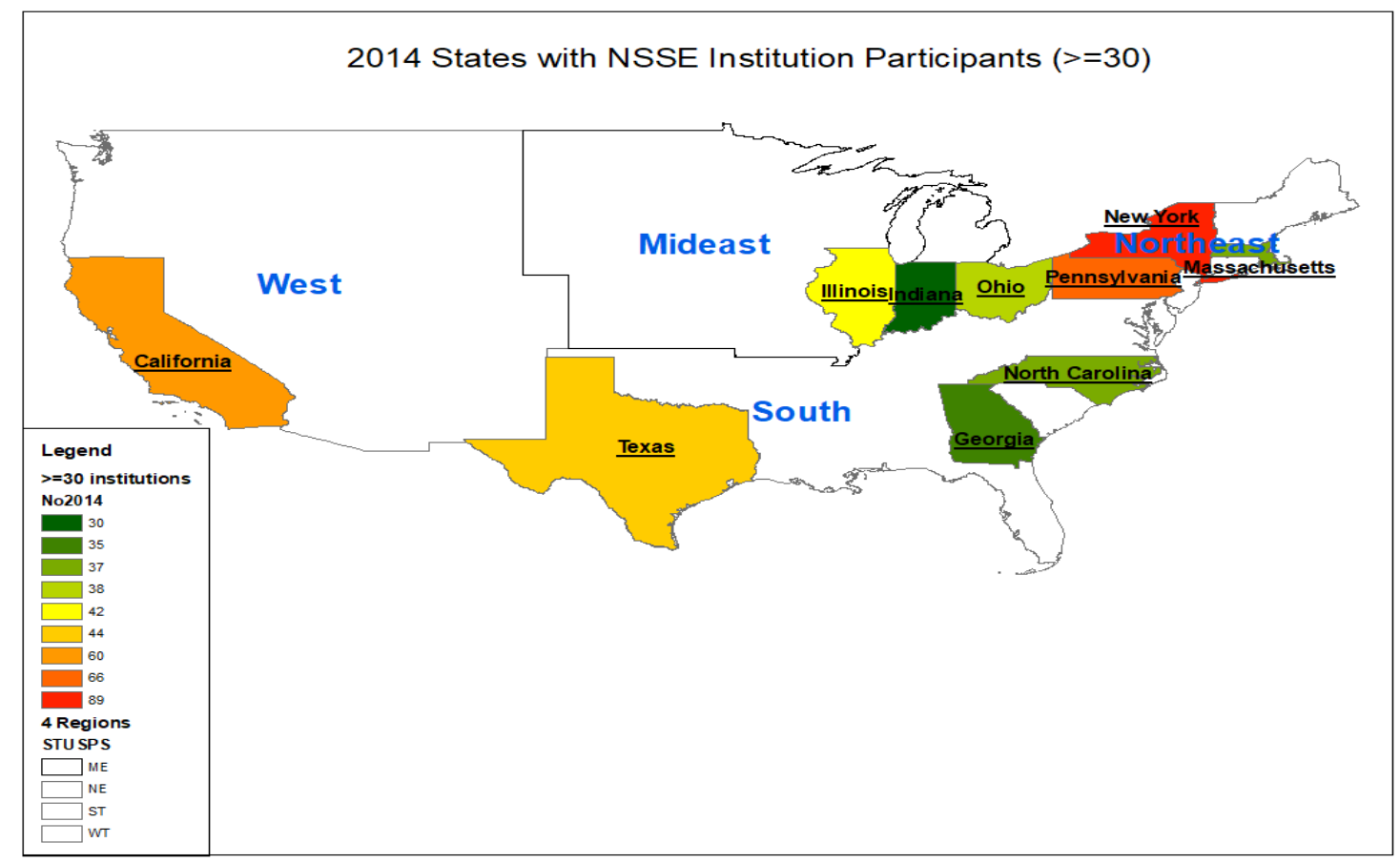

Figure 3. 2014 States with NSSE Institution Participants(>=30) 


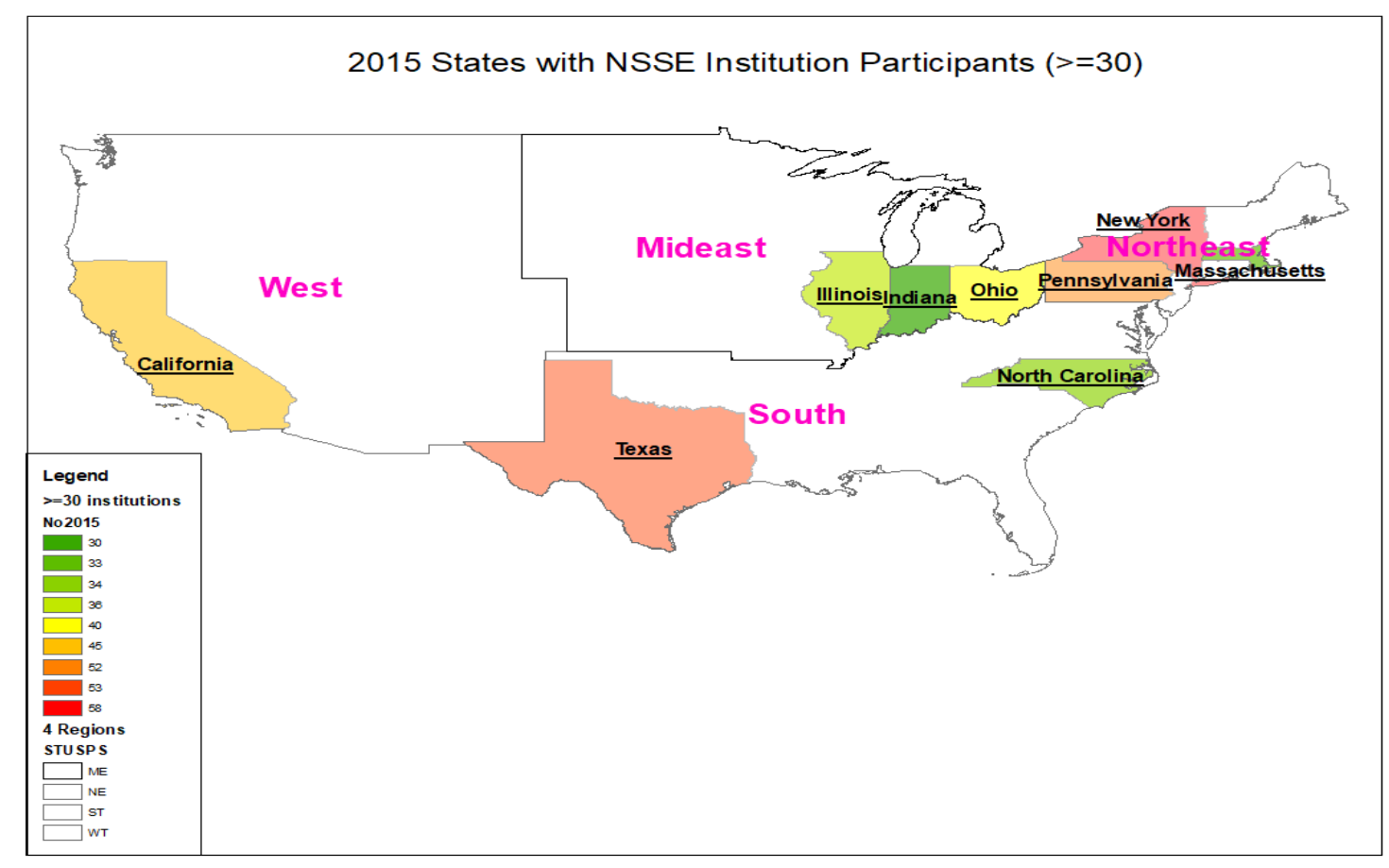

Figure 4. 2015 States with NSSE Institution Participants(>=30)

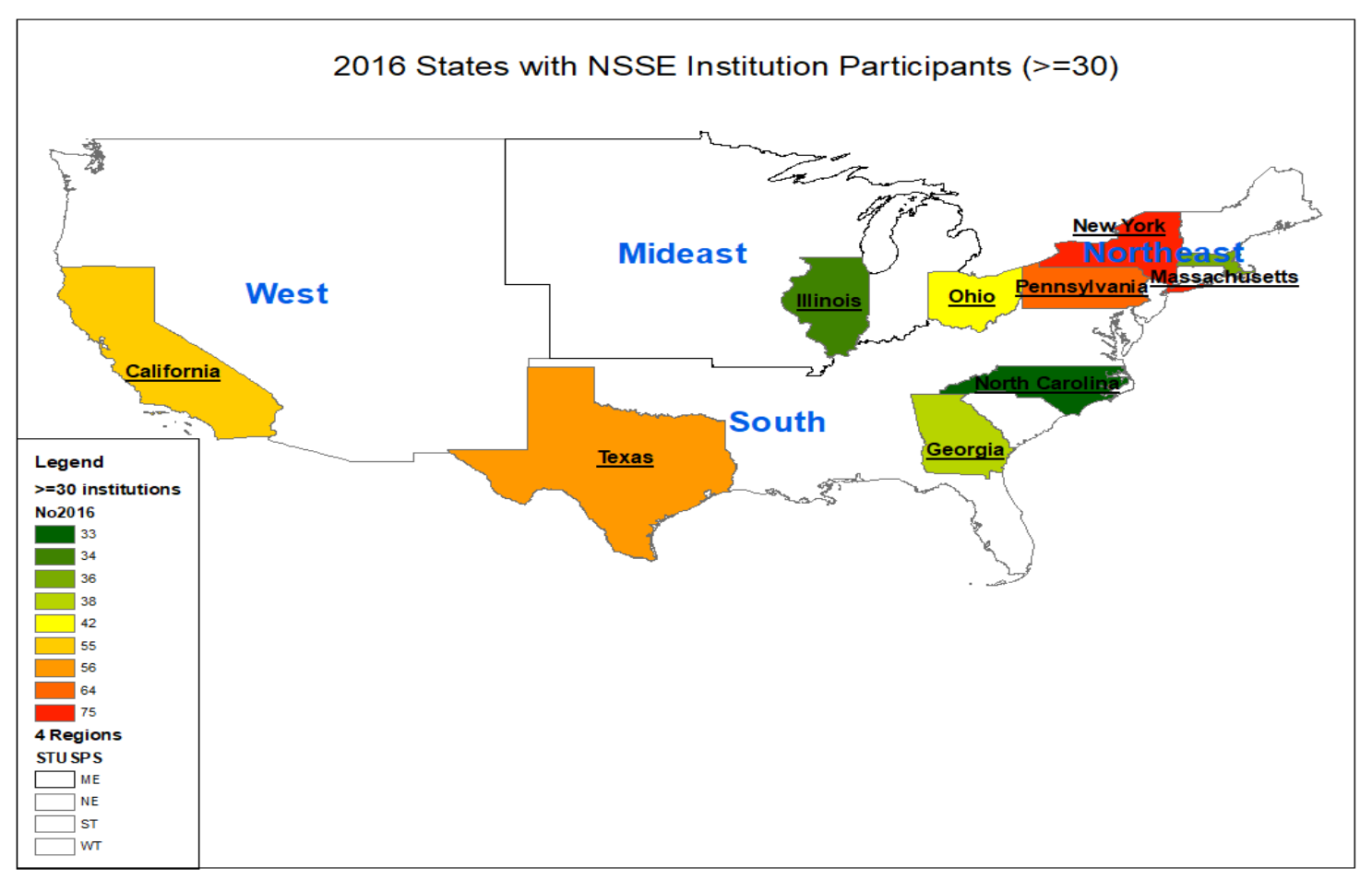

Figure 5. 2016 States with NSSE Institution Participants (>=30) 


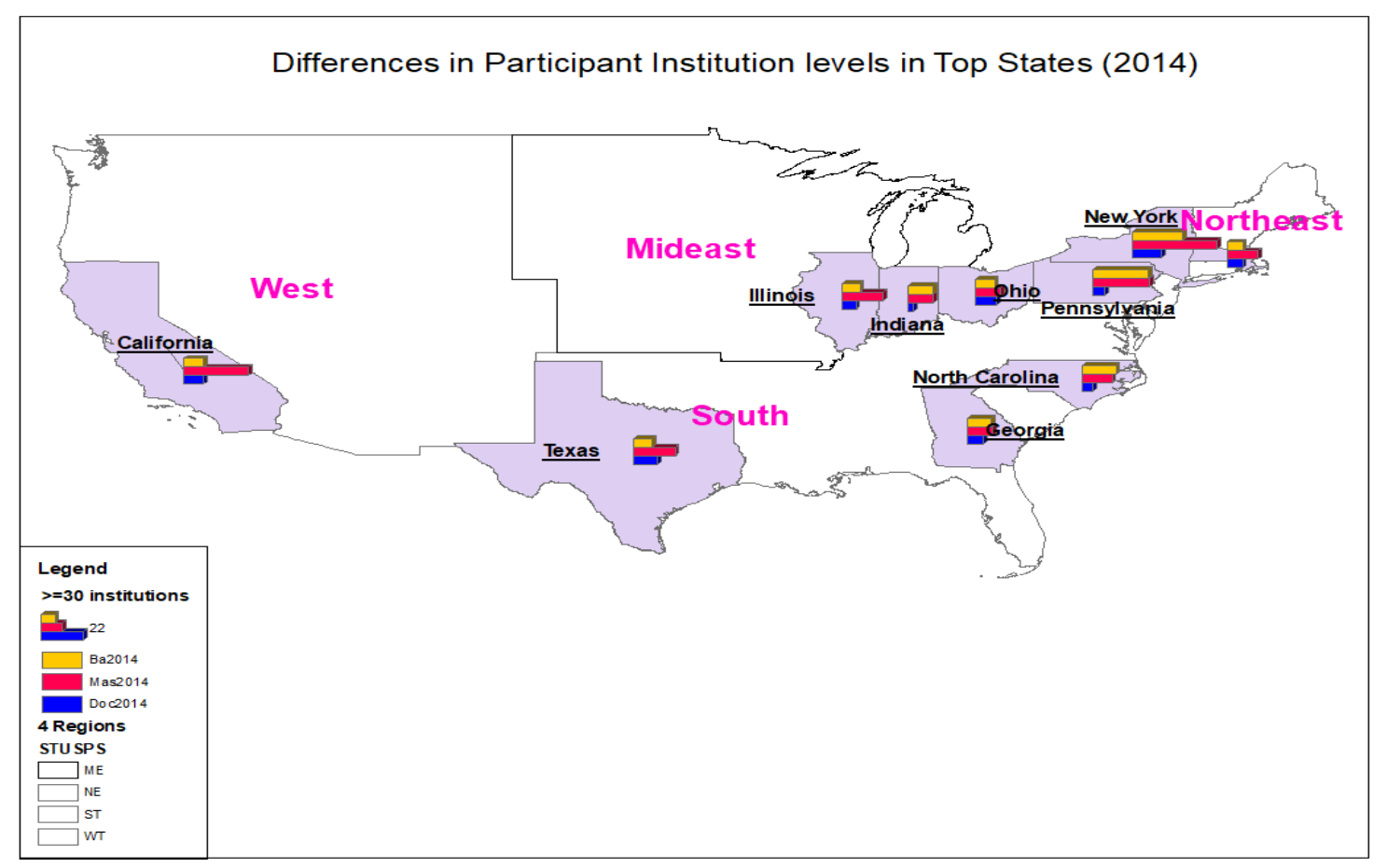

Figure 5. Differences in Participant Institution levels in Top States (2014)

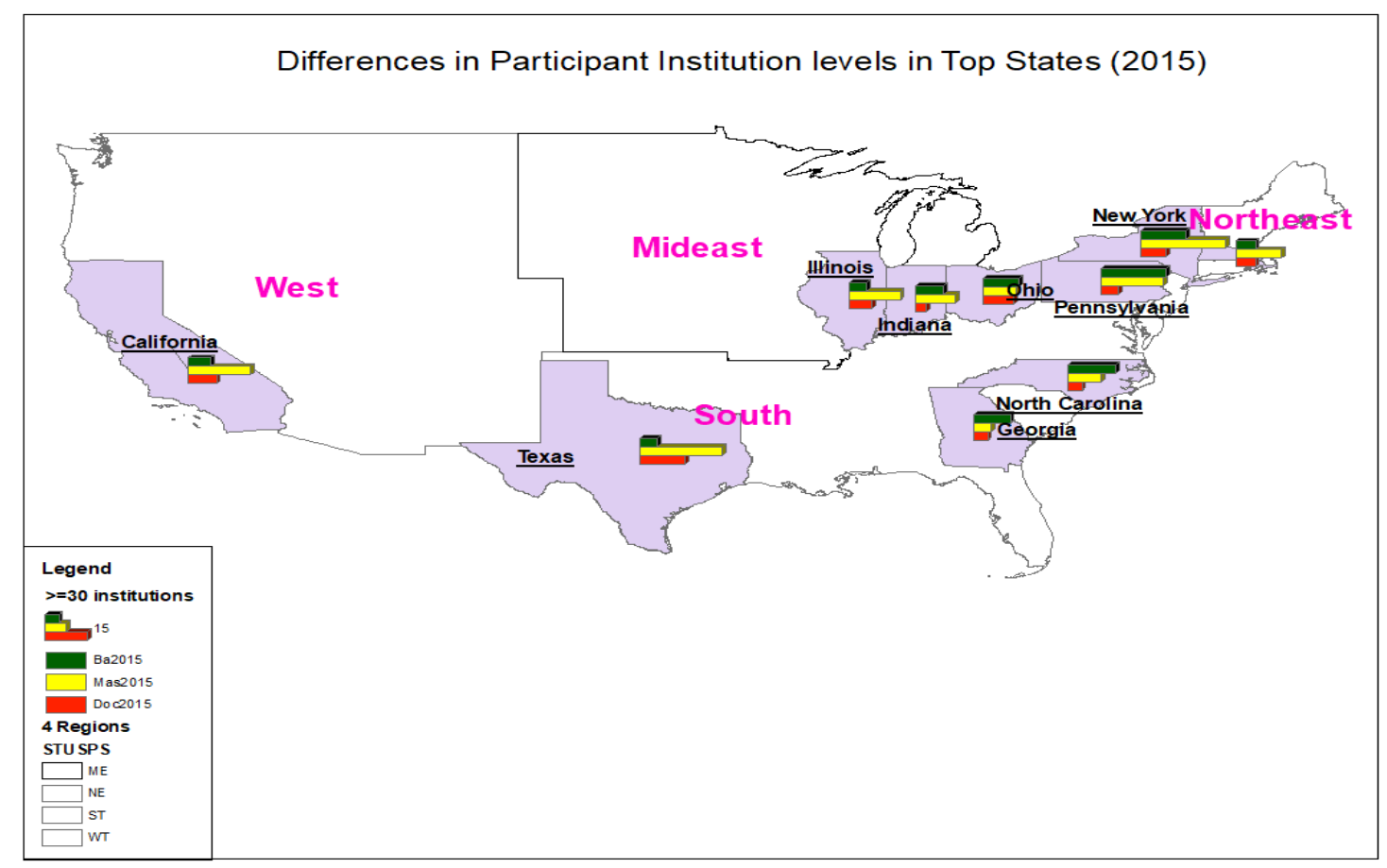

Figure 6. Differences in Participant Institution levels in Top States (2015) 


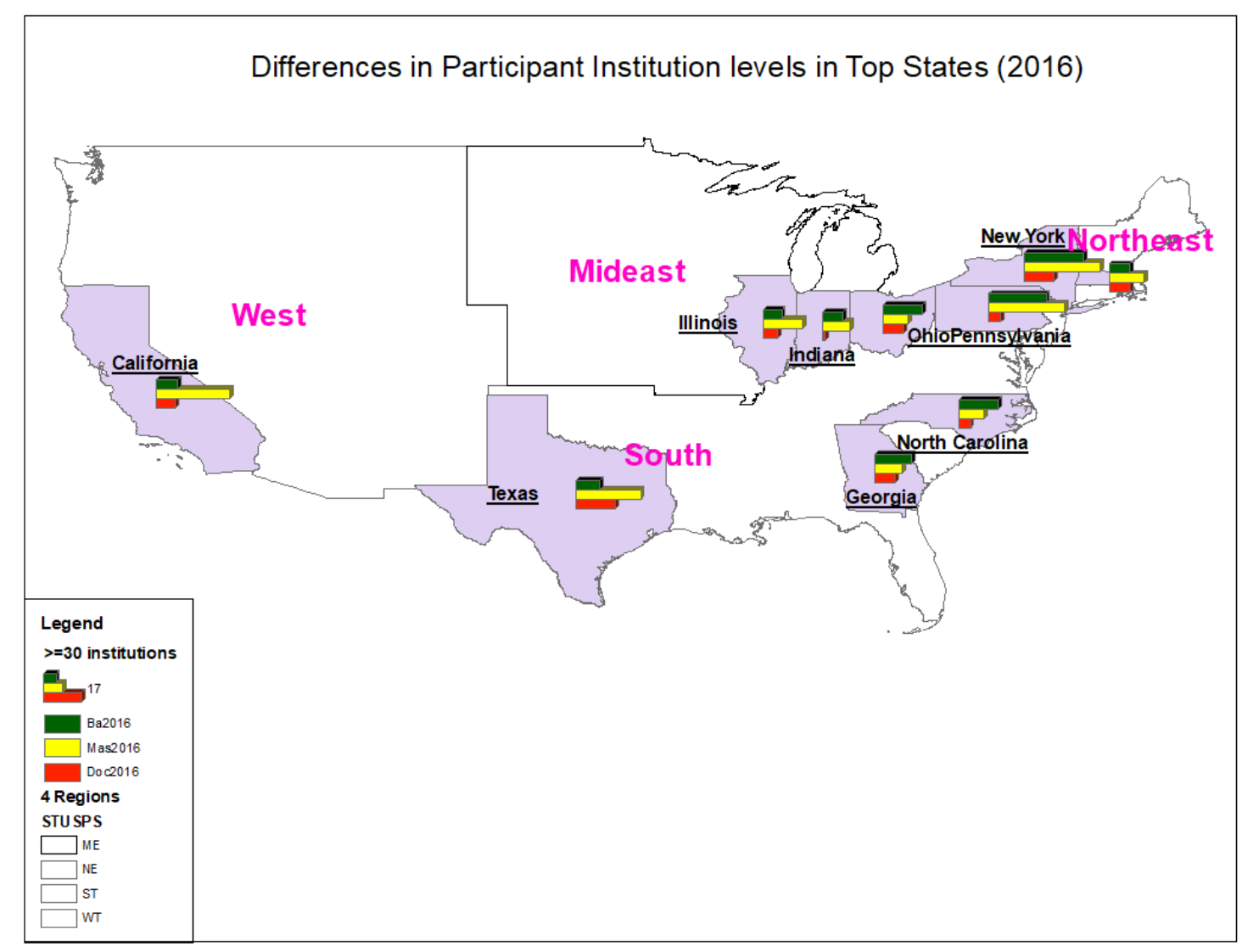

Figure 7. Differences in Participant Institution Levels in Top States (2016)

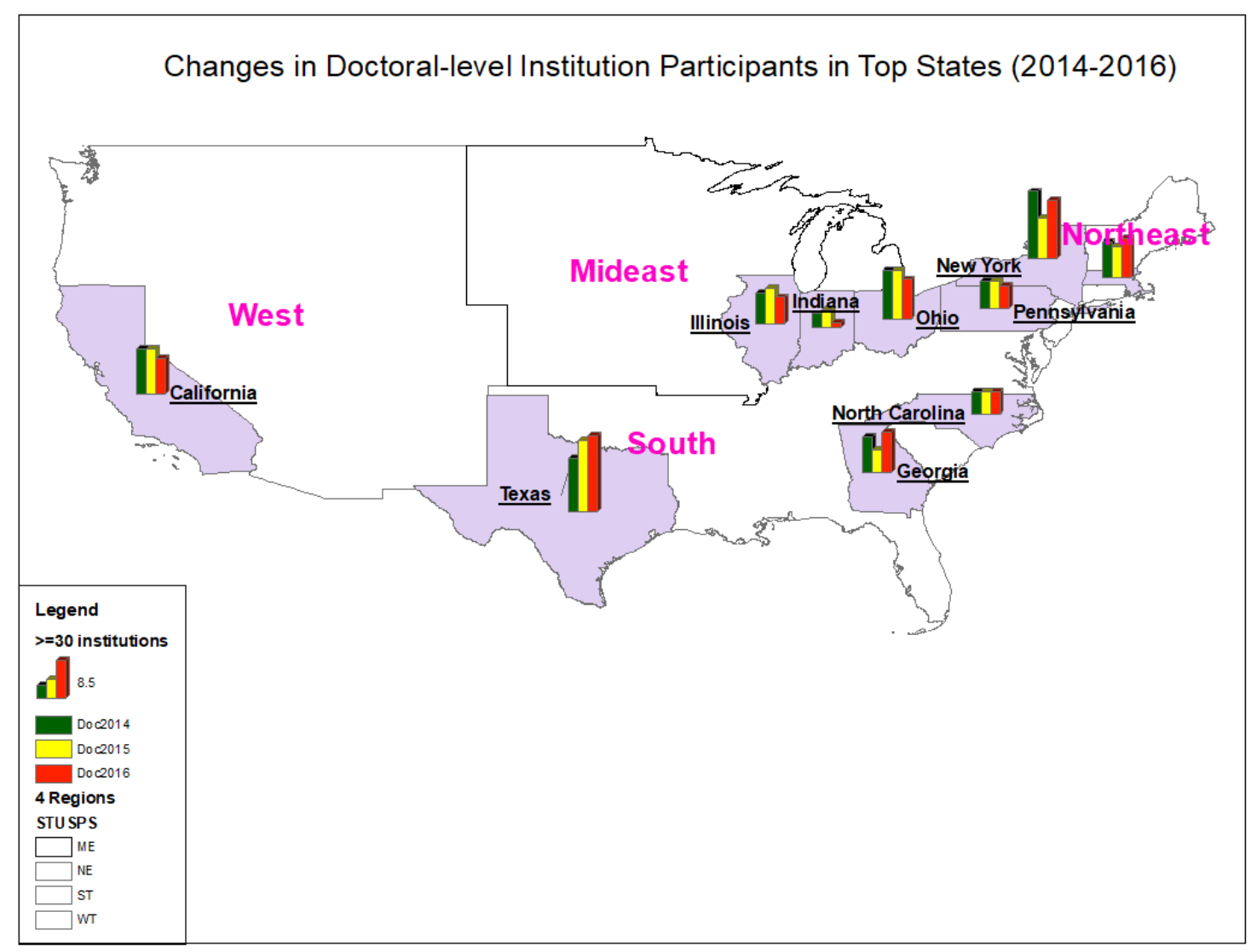

Figure 8. Differences in Participant Institution Levels in Top States (2016) 


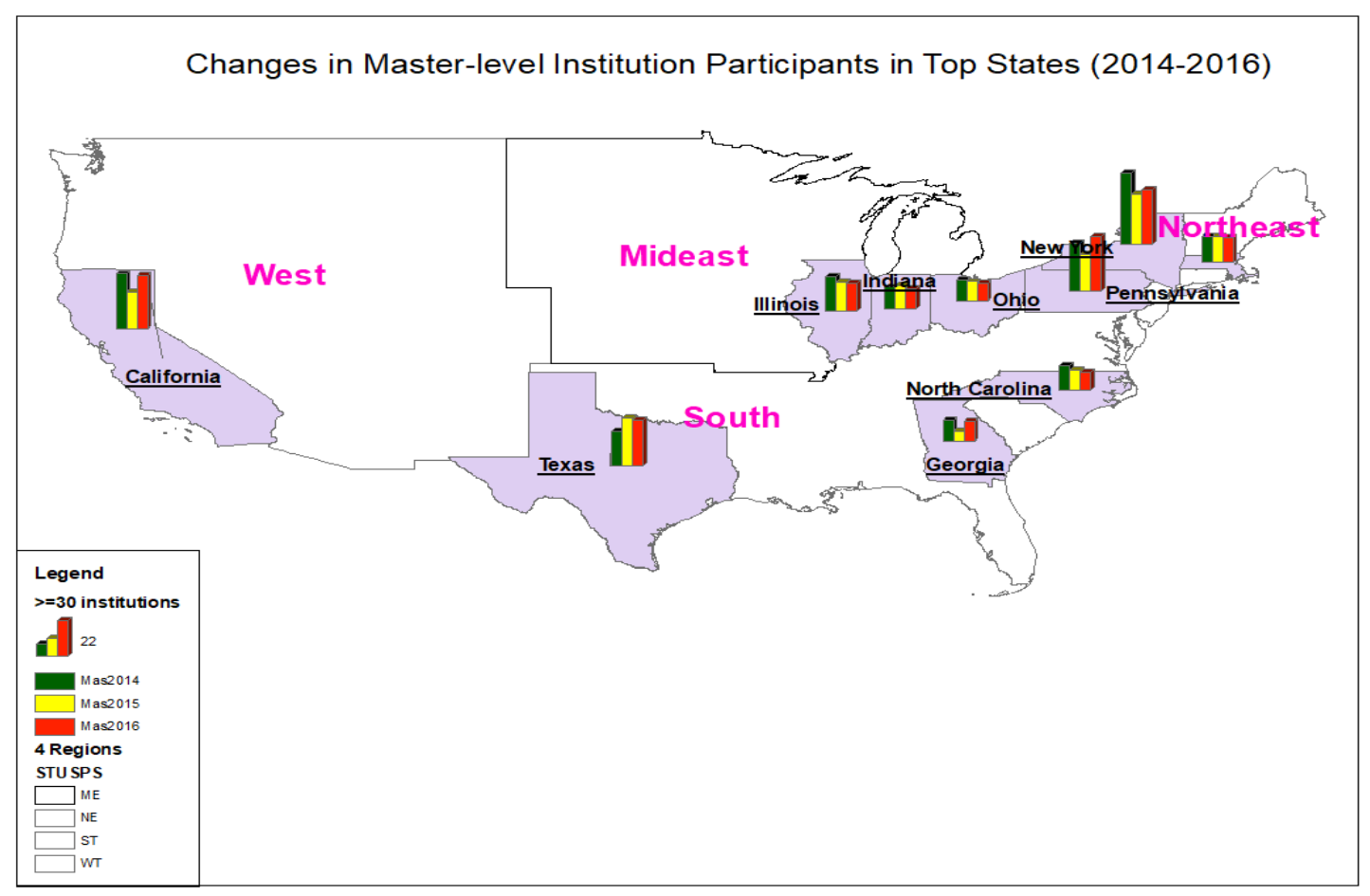

Figure 6. Changes in Master-level Institution Participants in Top States (2014-2016)

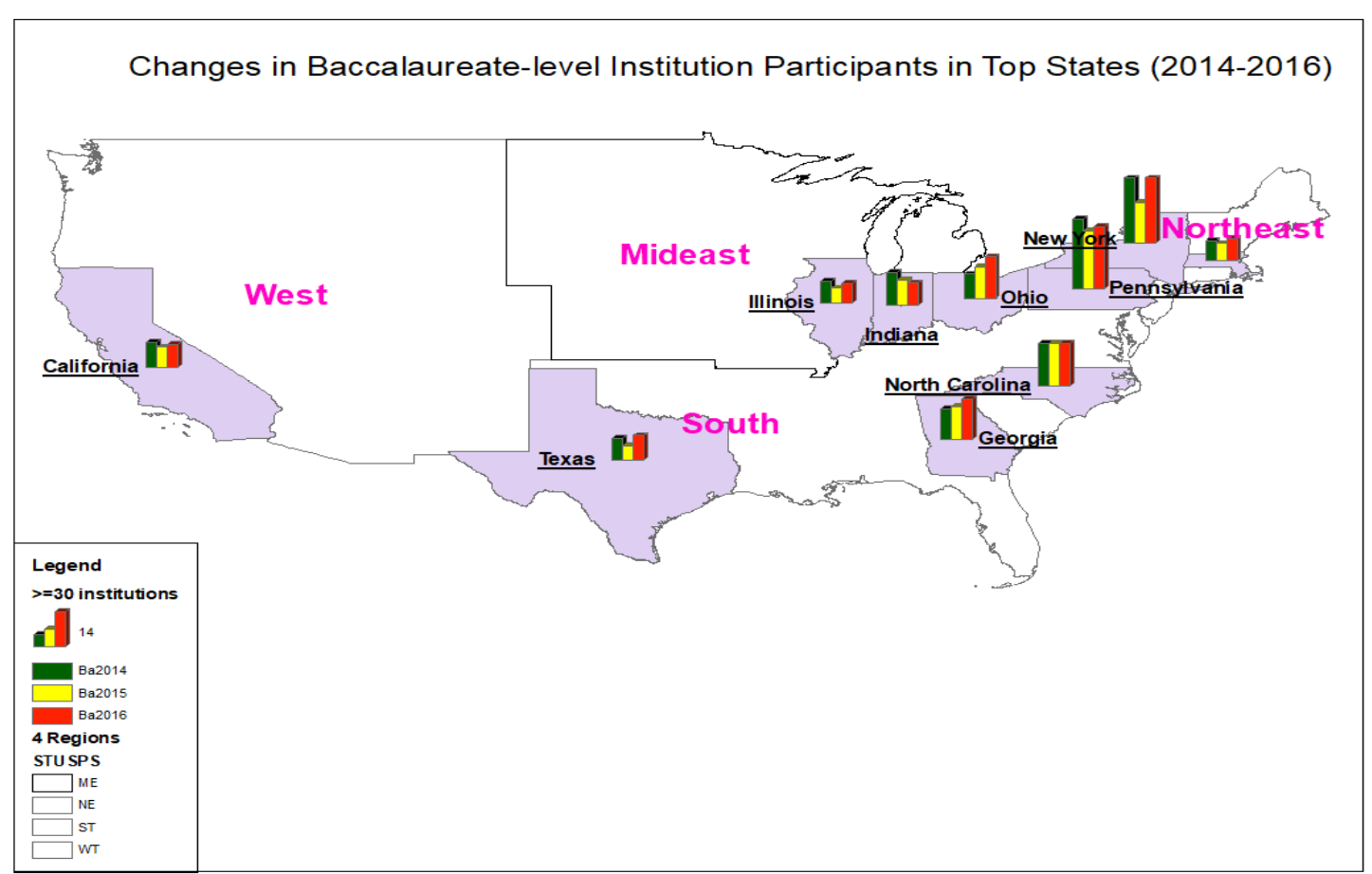

Figure 10. Changes in Baccalaureate-level Institution Participants in Top States (2014-2016) 